\title{
Combining NT3-overexpressing MSCs and PLGA mi- crocarriers for brain tissue engineering: A potential tool for treatment of Parkinson's disease
}

\author{
Hanieh Moradian ${ }^{1,2}$, Hamid Keshvari², Hamidreza Fasehee ${ }^{1}$, Rassoul Dinarvand ${ }^{3}$, \\ Shahab Faghihi ${ }^{1, *}$
}

${ }^{I}$ Tissue Engineering and Biomaterials Research Center, National Institute of Genetic Engineering and Biotechnology (NIGEB), Tehran, 14965/161, Iran

${ }^{2}$ Faculty of Biomedical Engineering, Amirkabir University of Technology, Tehran 15875/4413, Iran

${ }^{3}$ Novel Drug Delivery Lab, Department of Pharmaceutics, Faculty of Pharmacy, Tehran university of Medical Sciences, Tehran, Iran

\footnotetext{
${ }^{*}$ Shahab Faghihi, Tissue Engineering and Biomaterials Research Center, National Institute of Genetic Engineering and Biotechnology (NIGEB), Tehran 14965/161 Iran E-mail: sfaghihi@nigeb.ac.ir; Shahabeddin.faghihi@mail.mcgill.ca Phone: +98 21 44580386, Fax: +98 2144580386
} 


\begin{abstract}
Parkinson's disease (PD) is a progressive neurodegenerative disorder that characterized by destruction of substantia nigrostriatal pathway due to the loss of dopaminergic (DA) neurons. Regardless of substantial efforts for treatment of PD in recent years, an effective therapeutic strategy is still missing. In a multidisciplinary approach, bone marrow derived mesenchymal stem cells (BMSCs) are genetically engineered to overexpress neurotrophin-3 ( $n t-3$ gene) that protect central nervous system tissues and stimulates neuronal-like differentiation of BMSCs. Poly(lactic-co-glycolic acid) (PLGA) microcarriers are designed as an injectable scaffold and synthesized via double emulsion method. The surface of PLGA microcarriers are functionalized by collagen as a bioadhesive agent for improved cell attachment. The results demonstrate effective overexpression of NT-3. The expression of tyrosine hydroxylase (TH) in transfected BMSCs reveal that NT-3 promotes the intracellular signaling pathway of DA neuron differentiation. It is also shown that transfected BMSCs are successfully attached to the surface of microcarriers. The presence of dopamine in peripheral media of cell/ microcarrier complex reveals that BMSCs are successfully differentiated into dopaminergic neuron. Our approach that sustains presence of growth factor can be suggested as a novel complementary therapeutic strategy for treatment of Parkinson disease.
\end{abstract}

Key words: Parkinson's disease; DA neurons; Regenerative medicine; Neurotrophin-3; PLGA microcarriers. 


\section{Introduction}

Parkinson's disease (PD), the second most prevalent progressive neurodegenerative disorder of the aging central nervous system (CNS), is characterized by continuous and selective degeneration of dopaminergic neurons $[1,2]$. The current approaches for treatment of PD are the oral administration of Levadopa (L-Dopa) as a drug therapy method [3, 4] and surgical procedures such as deep brain stimulation (DBS) [5]. Levadopa (L-Dopa), a precursor of dopamine, is mainly used in combination with a peripheral dopa decarboxylase inhibitor [6]. However, long term administration of L-Dopa would adversely impact its therapeutic effect in a way that remaining native neurons further degenerate and subsequently cause severe side effects like involuntary movements $[1,6]$. Deep brain stimulation of neurons for production of dopamin merely provides symptomatic relief and do not associate the underlying degenerative process related to the disease [7]. As a consequence, the patients always exhibit progressive worsening over the time [7, 8]. All these facts accentuate the vital need to develop novel therapeutic methods for Parkinson's disease.

In order to overcome these challenges, researchers have explored preventative and curative strategies mainly based on neuroprotection, and neuroregeneration $[9,10]$. The methods based on the former prevent the dopaminergic neurons from unwanted death while the latter contributes cell replacement or cell therapy [1]. Cell therapy is considered as an exciting therapeutic method for repair of defected site in the brain tissue of PD's patients [11]. However, there are several key issues that need to be considered in order to effectively utilize cell therapy including the neuronal cell source and their microenvironment that physically and biologically mimic the host parenchymal tissue [12].

Mesenchymal stem cells are proposed as the best source for cell-based therapies of neurological disorders because of their remarkable neuro-differentiational characteristic, immunomodulatory features [13], and capacity to migrate toward source of lesions in brain [14]. Moreover, some studies have reported that bone marrow mesenchymal stem cells (BMSCs) can be induced into DA- neurons due to their ability to secret tyrosine hydroxylase (TH) [15] and other neural markers $[10,16,17]$. Also, some studies showed that transplantation of MSCs into adult intact rats lead to significant elevation of TH secretion and DA levels in the striatum $[10,18]$. The steady motor improvement of hemiparkinsonian rat in vivo with no significant adverse effects 
after MSCs transplantation has been also reported [19]. Hence, many researchers have recently utilized MSCs as cell source for treatment of PD since they can be differentiated into neuron like cells before in vivo transplantation [12, 20-22]. The use of chemical cues [23], cytokines [24], co-culture with nerve cells [25], and transfection of genes responsible for differentiation of MSCs to DA neurons [26] have been recently reported. Despite many advantages in the application of MSCs, stem cell-based therapies for PD face serious challenges such as low cell survival, uncontrollable differentiation, and unsuccessful engraftment due to lack of physical support of the cells $[1,27]$. In recent years, scientists have used tissue engineering as promising strategy for cell based therapies [12, 28, 29]. Using this approach, it is possible to improve cell engraftment to the host tissue after transplantation by providing 3D supportive structure. Indeed, scaffolding materials may present a biomimetic structure of different extracellular matrix (ECM) components that could stimulate cell survival and differentiation [27, 30]. It is however essential to optimize biological [31], mechanical [32,33] and physicochemical properties [34] of scaffolding material before they can be successfully employed. In brain tissue engineering, the size of the scaffold is one of the most crucial issues as it has to be small enough to be injectable into the site of lesion in deep brain [1,27]. Many research groups have developed microcarriers as cellular scaffolds to provide long-term survival of transplanted cells [27, 31, 35, 36]. In order to mimic the natural environment of the host tissue, the microcarriers could be loaded with related growth or signaling factors to increase cell's survival $[12,37]$. The efficacy of this approach has been successfully evaluated in rat model using PC12 cells combined with PLGA microcarrier which released nerve growth factors (NGF) [12, 27, 31]. Despite of interesting achievements obtained by these reports, the use of such systems is challenging mostly due to the short half-life of growth factors $[12,31]$. Furthermore, the growth factor will be depleted even by sustain release over a long period of time $[12,38]$. To overcome these obstacles, cells could be genetically engineered to produce their essential signaling factors which not only meet their own demand but also can influence adjacent cells via paracrine pathway [17, 26, 38].

In this study for the first time a multidisciplinary strategy consists of cell therapy, genetic and tissue engineering is employed to develop a new therapeutic approach as a potential treatment for PD. A genetic construction encoding neurotrophin-3 (NT-3), a member of neurotrophin family which plays a protective role in injured central nervous system (CNS), was designed and fabricated. Subsequently, bone marrow derived mesenchymal stem cells (BMSCs) were genetically 
engineered to overexpress NT-3 which could stimulate the neuronal-like differentiation of BMSCs and promote regeneration of damaged tissue. The overexpression of NT-3 in BMSCs and the expression of genes in neuronal development pathway were analyzed using RT-PCR whereas the expression of tyrosine hydroxylase $(\mathrm{TH})$ was assessed by Immunocytochemistry (ICC). The PLGA microcarriers were then designed and synthesized via double emulsion method as an injectable scaffold for the NT-3 overexpressing BMSCs. The surface of PLGA microcarriers were functionalized by collagen as a bioadhesive agent to better support cellular attachment. As far as our knowledge, this is the first attempt to use a multidisciplinary strategy to overcome the barriers in development new therapeutic approach for PD. 


\section{Experimental Methods}

\subsection{Materials}

PLGA (RG 504H), polyethylene glycol (PEG 400), Poly(vinyl alcohol), human serum albumin (HSA), sodium dodecyl sulfate (SDS), polyacrylamide, 4',6-diamidino-2-phenylindole (DAPI), EDC, sulfo-NHS and MES buffer were obtained from Sigma-Aldrich; bovine collagen solution, type I (3mg/ml) was purchased from PureCole (USA); Plasmid DNA encoding enhanced green fluorescent protein (pEGFP) was purchased from Invitrogen (USA), plasmids were purified via Qiagen Plasmid Maxi Kit (Qiagen, Germany), Lipofectamine® 2000, Trizol, and cDNA transcription kit were obtained from Life Technologies (USA), fetal bovine serum (FBS), alpha-MEM media, opti-MEM serum-free media, PBS buffer, Trypsin/EDTA and penicillinstreptomycin were purchased from GIBCO (USA); MTT (3-(4,5-dimethylthiazol-2-yl)-2,5- diphenyltetrazolium bromide) assay kit was obtained from Roche (Germany), all antibodies were from abcam (UK).

\subsection{Construction of plasmid DNA encoding NT-3}

Total RNA was extracted by TRIZOL reagent (Invitrogen) from mouse brain tissue according to the manufacturer's instructions. Subsequently, $5 \mathrm{mg}$ of total RNA was converted into cDNA using reverse transcriptase (RT) and random hexamer as primer (Oligo dT), based on the kit protocol (Fermentas). To amplify the coding sequence of $n t-3$ form total cDNA, the $n t-3$ specific

oligonucleotide primers were designed based on gene bank sequences of $n t-3$ gene. For cloning the resultant PCR product into pIRES-2-EGFP plasmid, XhoI site in the forward sequence and BamHI site in the reverse primer were incorporated. The resulted primer sequences were as follows: 5'GGGGCTCGAGATGTCCATCTTGTTTTATGTG3' (Tm=56 C; Forward) and 5'GGGGGGATCCTCATGTTCTTCCAATTTTTCTC3' (Tm=58 ${ }^{\circ} \mathrm{C}$; Reverse). Amplification was performed using Premix Taq PCR Kit (Fermentas) by standard PCR program with denaturation at $94^{\circ} \mathrm{C}$ for $45 \mathrm{~s}$, annealing at $48^{\circ} \mathrm{C}$ for $30 \mathrm{~s}$, extension at $72^{\circ} \mathrm{C}$ for $45 \mathrm{~s} \mathrm{(30} \mathrm{cycles),} \mathrm{and} \mathrm{a} \mathrm{final}$ extension step at $72^{\circ} \mathrm{C}$ for $5 \mathrm{~min}$. Amplified products were then electrophoresed on $1.5 \%$ agarose gel to check the primary accuracy of size and further purification by recovery from the gel via PCR purification kit (Fermentas). In order to create recombinant IRES-2-EGFP-NT-3 plasmid DNA, the pIRES-2-EGFP plasmid DNA and the resultant purified PCR product from previous step were both digested by restriction endonuclease of XhoI and BamHI (Fermentas) and 
subjected to agarose gel electrophoresis to obtain vector fragments. The purified vector (pIRES2-EGFP) and targeted gene (nt-3 gene) were mixed at 3:1 molar ratioandligated with T4 DNA ligase (Promega) for $18 \mathrm{~h}$ at $16^{\circ} \mathrm{C}$. The ligated products were then transformed into component E. colitop 10 cells and 10 clones were randomly selected on medium containing kanamycin. The recombinant plasmids were isolated from positive clones by using a Plasmid Miniprep Kit (Roche) and thosethat were contained the NT-3 gene were amplified to extract plasmid using a plasmid larger-scale (Maxi) preparation kit (Qiagen). The nucleotide size of the cloned cDNA was verified by digestion of recombinant plasmid followed by evaluation on agarose gel electrophoresis. The sequence of the inserted gene was additionally verified by DNA sequencing. The concentration of recombinant plasmid solution was measured by NanoDrop 1000 spectrophotometry (Thermo Fisher Scientific).

\subsection{BMSCs isolation and primary culture}

Rat bone marrow-derived mesenchymal stem cells (BMSCs) were prepared as described previously [39]. Briefly, BMSCs isolated from long bones (i.e. femur and tibia) of 6 weeks old male Wistar rats (Animal Science Department, University of Tehran). Following euthanasia by pentobarbital $20 \%(\mathrm{v} / \mathrm{v})$, the bones were aseptically dissected and cleaned of soft tissue and washed with PBS. The ends of the bones were cut and marrow was flushed out from the tibiae and femora with $5 \mathrm{ml}$ of $\alpha$-Minimum Essential Medium ( $\alpha$-MEM) using a 23-gauge needle and syringe.

The cells were centrifuged (1000 rpm, $5 \mathrm{~min}$ ) and resuspended in fresh $\alpha$-MEM medium containing $15 \% \mathrm{FBS}, 100 \mathrm{U} / \mathrm{ml}$ penicillin and $100 \mu \mathrm{g} / \mathrm{ml}$ of streptomycin. Cells were seeded in a 25 $\mathrm{cm} 2$ and incubated at $37{ }^{\circ} \mathrm{C}$ in $5 \% \mathrm{CO} 2$ and $90 \%$ humidity. After $24 \mathrm{~h}$, non-adherent cells were discarded and medium was exchanged. The adherent cells were detached with $0.25 \%$ tryp$\sin$ /EDTA at day 7 . Following cultures were passaged at 5-7 day intervals and expanded to 5 passages for further experiments.

\subsection{Transfection of BMSCs with pIRES-2-EGFP-NT-3}

Recombinant plasmid DNA encoding EGFP and NT-3 under the control of a CMV promoter (pIRES-2-EGFP-NT-3) was used as an exogenous gene. BMSCs were seeded at a density of $13 \times 10^{4}$ cells per well in adherent 24 well plates in order to reach $70 \%$ confluence. Media was exchanged with $500 \mu$ l of pre-warmed OptiMEM serum-free media and incubated at $37{ }^{\circ} \mathrm{C}$ one hour before transfection. Subsequently, lipoplexes were formed with Lipofectamine 2000 and 
recombinant pDNA using the manufacturer's instruction. Briefly, recombinant plasmid (pIRES2-EGFP-NT-3) and lipid solution were diluted in Opti-MEM media separately at room temperature. After $5 \mathrm{~min}$ recombinant plasmid /lipid complexes were formed at ratio of 1:2(w/v) by dropwise addition of lipid dilution in recombinant plasmid. Transfection medium (100 $\mu$ l) were then added to each well and remained in contact with cells for $4 \mathrm{~h}$. Finally, the transfection media was removed and cells were rinsed with PBS. The fresh complete culture medium was added to the cells and incubated at $37{ }^{\circ} \mathrm{C}$ to express the NT-3. The transfection efficiency was assessed via fluorescence microscope (Nikon, Germany) imaging after $60 \mathrm{~h}$. The transfection media without lipoplexes was used as negative control.

\subsection{Evaluation of neuronal differentiation using $q R T-P C R$}

The over expression of $n t-3$ and subsequent neuronal differentiation of BMSCs, were assessed by quantitative real-time polymer chain reaction (qRT-PCR). Total RNA of transfected BMSCs was extracted using trizol reagent and RNA integrity was checked on 1\% agarose gels. Reverse transcription of RNA to cDNA was then performed using cDNA transcription kit (Fermentas). Quantitative real-time PCR was performed (lightcycler PCR-USA) with $20 \mu 1$ SYBR Green reaction system. The primer's sequences are presented in Table. 1. PCR amplification was performed for 45 cycles. The housekeeping gene (GAPDH) was used to normalize gene expression levels.

\subsection{Evaluation of neuronal differentiation using TH immunocytochemistry}

Cells were prepared for immunocytochemical assay one week after transfection with pIRES2-EGFP-NT-3. Cells were fixed with $4 \%$ paraformaldehyde at $4{ }^{\circ} \mathrm{C}$ for $30 \mathrm{~min}$ and washed three times with 0.01 M PBS. Cells were then incubated in blocking serum (10\% goat serum and $0.1 \%$ Triton X-100 in PBS) for 30 min followed by incubation in rabbit anti-Tyrosine hydroxylase (TH) antibody solution (abcam , 1:1000) for $24 \mathrm{~h}$ at $4^{\circ} \mathrm{C}$. For color detection of TH, a goat polycolonal antibody to rabbit IgG (abcam , 1:200) was used according to the supplier's instruction.

\subsection{Synthesis and characterization of PLGA microcarriers}

Poly(D,L-lactide-co-glycolide) with lactic: glycolic units ratio of 50:50 (Mw=38,000 Da) was used to synthesize microcarriers via water-in-oil-in-water (W/O/W) emulsion-extractionevaporation process $[31,36]$. Briefly, internal aqueous phase including $60 \mathrm{~mL}$ of $16 \mathrm{mM}$ citrate 
buffer ( $\mathrm{pH}=6$ ), $2.56 \mathrm{mg}$ of human serum albumin (HSA), and $90 \mathrm{~mL}$ of polyethylene glycol (PEG 400) was emulsified by sonication in an organic solution (medial oil phase) containing 75 mg of PLGA and organic solvent at $4^{\circ} \mathrm{C}$. The resultant emulsion was injected to a $4^{\circ} \mathrm{C}$ aqueous solution of 4\% (w/v) Poly(vinyl alcohol) (PVA) (Mw=27,000 Da) containing isopropanol (10\% $\mathrm{v} / \mathrm{v})$, using controlled rate injection pump. To remove organic solvent, the double emulsion was poured into $400 \mathrm{~mL}$ of water containing $10 \% \mathrm{NaCl}$ under magnetic stirring. The resulting microparticles were washed five times with deionized water and collected by filtration and freezedried. Table. 2 presents the parameters involved in synthesis of microparticles in order to reach desirable size and polydispersity index (PDI). Microparticles average size was measured using Mastersizer instrument (Malvern, UK). PLGA microparticles were suspended in aqueous solution containing 1\% PVA as stabilizer and sonicated prior to analysis. The particles were analyzed by volume mean diameter mode which represents the most frequent diameter and coefficient of variation for size distribution (i.e. PDI). The scanning electron microscopy (SEM) was conducted in order to evaluate surface morphology and stability of microcarriers. In this regard, the stability of microparticles against degradation in growth media was assessed via incubation in $\mathrm{CO}_{2}$ incubator (normal cell culture condition) after one week and one month. The microcarriers were washed in PBS, fixed with glutaraldehyde $1 \%$ and dehydrated with a series of ethanol, followed by coating a thick layer of gold and examined with SEM.

\subsection{Surface coating of PLGA microcarrier with collagen}

In order to facilitate cells attachment on the surface of microcarriers, collagen was used as for surface functionalization. $100 \mathrm{mg}$ of PLGA microparticles were added to the MES buffer solution (0.05 M, pH=5) containing appropriate amount of EDC and NHS. The resulting solution was agitated under magnet stirring for $4 \mathrm{~h}$ at room temperature followed by washing with deionized water to remove unreacted substitutes. The precipitation was resuspended in $10 \mathrm{ml}$ of PBS (0.01 M, pH=7.5). Subsequently, $0.2 \mathrm{mg}$ collagen was added to this solution and mixed overnight under magnet stirring. The functionalized microcarriers were washed three times and lyophilized. In order to confirm collagen attachment on the surface of microcarriers, the particles were characterized using SDS-PAGE technique. In this way, $1.5 \mathrm{mg}$ of collagen-functionalized microparticles were dissolved in sample loading buffer $(62.5 \mathrm{mM}$ Tris- $\mathrm{HCl}, \mathrm{pH} 6.8,2 \% \mathrm{w} / \mathrm{v}$ SDS, $10 \%$ glycerol). The resultant solution were electrophoresed on tris-glycine-SDS-polyacrylamide 
gel and stained with coomassie brilliant blue R-250 according to standard protocols. The gel evaluated after destaining by $7 \%(\mathrm{v} / \mathrm{v})$ acetic acid. The pure collagen was used as control.

\subsection{PLGA microcarrier/NT-3 overexpressing cells}

BMSCs were seeded on the surface of microcarriers two days after transfection. To assess the effect of collagen coating on cell adhesion, the NT-3 overexpressing cells were cultured with PLGA microcarriers with and without collagen coating. Cells were added with a density of $1.5 \times 10^{5}$ to $1.5 \mathrm{mg}$ of particles in low adherent 24 -well plate. Cell attachment was assessed after 24 h by optical microscopy, scanning electron microscopy, and fluorescent microscopy. For DAPI staining, cells were washed with PBS and fixed with 4\% paraformaldehyde following by addition of diluted DAPI solution. The staining media were removed after $5 \mathrm{~min}$, washed three times with PBS and optical and fluorescent imaging was performed. The cytotoxicity of PLGA microcarriers with and without collagen coating was evaluated using MTT assay. BMSCs were seeded in a 96-well plate at an initial density of 5000 cells with 0.05 mg PLGA microcarriers. After overnight incubation, $10 \mu \mathrm{l}$ of MTT reagent $(5 \mathrm{mg} / \mathrm{mL})$ was added to each well and incubated for additional $4 \mathrm{~h}$. The medium was exchanged with $100 \mu \mathrm{L}$ DMSO to dissolve the formazan crystals formed as a result of MTT cleavage by viable cells. Absorbance was measured at $570 \mathrm{~nm}$ by ELISA plate reader (Labsystems multiscan, Rodon, Netherlands). Non-transfected cells were used as control.

\subsection{Statistical analysis}

Each experiment was performed at least in triplicate. All results are summarized as means \pm standard deviation and statistical differences were determined by analysis of variance followed by independent sample t-test using SPSS software version 21. Results were considered statistically significant when $p<0.05$. 


\section{Results}

\subsection{Identification of recombinant pDNA construction}

Figure. 1A presents the steps for preparation of recombinant plasmid DNA encoding NT-3. The aim was to prepare a DNA construct that over express both reporter gene (EGFP) and target gene (nt-3), simultaneously. After translation of DNA to protein sequence via online software of NCBI, the presence of signal peptide was assessed with SignalP software. As it can be seen in Figure. 1B the existence of signal peptide among the first 23 amino acids was verified.

Figure. 1C demonstrates pIRES-2EGFP (lane $1 \& 2$ ) at $5.3 \mathrm{~kb}$ and pIRES-2EGFP-NT-3 (lane $3 \& 4)$ in a higher level as it contains $n t-3$ gene. The lane 5 shows the result of single digestion of pIRES-2EGFP-NT-3 with BamHI. The accuracy of pIRES-2EGFP-NT-3 production was evaluated with BamHI and XhoI cleavage. The result is depicted in specific bands at $5.3 \mathrm{~kb}$ and 770 bp related to IRES-2-EGFP plasmid and $n t-3$ gene fragment, respectively (Figure. $1 \mathrm{C}$, lane 6). After plasmid identification, the gels containing pIRES-2EGFP-NT-3 was recovered and DNA sequencing was performed in order to validate the $n t-3$ construction. The result of DNA sequencing was approved the successful production of pDNA encoding $n t-3$ gene (data not shown).

\subsection{BMSCs transfection}

To evaluate cells transfection with pIRES-2-EGFP-NT-3, optical and florescent microscopies were used $60 \mathrm{~h}$ post transfection. The images are presented in Figure. 2. The EGFP expression revealed by fluorescent green color indicates successful transfection of BMSCs. This evaluation may also imply the expression of the target gene i.e. $n t-3$ as they are presumed to transcript and translate at the same time in equal level.

\subsection{Differentiation of BMSCs into neuron-like cells}

In order to evaluate cell differentiation into neuron-like cells real-time PCR and immunocytochemistry were used. To verify stability of transgene expression after differentiation, several important and determining genes related to neuronal differentiation were selected for test after seven days. The results of RT-PCR confirmed the significant enhancement in expression level of nurr -1 and wnt -1 mRNA $(p<0.05)$. The data also showed high level of $n t-3$ and tyrosine hydroxylase mRNA expression in transfected cells. Undifferentiated BMSCs were used as control which they did not express neuron-specific markers while they expressed transcripts for enl, 
ptx3 and pax2 which are associated with dopaminergic neuron development (Figure 3A). There was no significant difference in en-1, pitx-3 and pax-2 mRNA expression between BMSCs and NT-3 overexpressing cells. All results were reported as relative mRNA expression of target gene over housekeeping gene (i.e. GAPDH).

The phenotype of transfected cells were also analyzed with optical microscopy which is exhibited in Figure. 3B. The image shows the gradual changes in cell phenotype toward neurons. In addition, immunocytochemical (ICC)- staining of NT-3 overexpressing cells with antibodies against TH protein was performed to identify dopaminergic neuronal differentiation. The results showed that this neuron like- cells were successfully expressed TH which is the most important protein in DA-neuronal differentiation (Figure 3C-D).

\subsection{Characterization of PLGA microspheres}

The mean size and polydispersity index (PDI) of PLGA microspheres were analyzed as the first factors for optimization. The results are shown in Table. 2. The optimal size which is reported to be around 120 micrometers with a relatively good homogeneity (i.e. minimum PDI) was obtained with reaction No. 6 (rotation speed of $300 \mathrm{rpm}$ and Eth:DiCh (30:70) as organic solvent). The particle size of $123.23 \mu \mathrm{m}$ with great homogeneity (PDI $=0.75)$ was obtained and selected for synthesis of PLGA microspheres to be used for further experiments. Figure 4.A-B shows the microparticle's diameters and optical image of the optimum sample.

After functionalization of microcarriers surface with collagen, the most efficient substrate for BMSCs attachment and differentiation, SDS-PAGE was used for confirmation. The results verified successful attachment of collagen to PLGA microcarriers surface as two determining bands $(130 \& 250 \mathrm{kDa})$ of pure collagen (lane 1) and PLGA functionalized with collagen (lane 2) were equal in two samples (Figure $4 \mathrm{C}$ ). In addition, the band in $220 \mathrm{kDa}$ confirmed the presence of HSA which was encapsulated in the core of microspheres.

The surface morphology of the PLGA microspheres was analyzed with scanning electron microscopy (SEM) and presented in Figure 5 (A, B). The adhesion molecules (i.e. collagen) covered the surface of the microspheres with a thin uniform layer and remained intact even after lyophilization (Figure 5 C, D). The stability of microparticles was qualitatively analyzed in term of degradation rate after one week and one month using scanning electron microscpy. Figure. 5 presents the gradual degradation of microparticles after incubation in culture media at $37^{\circ} \mathrm{C}$ 
which revealed more stable particles will degrade less. However, more degradation was observed after one month which would be an appropriate characteristic for tissue regeneration applications (Figure $5 \mathrm{G}, \mathrm{H})$.

\subsection{PLGA microcarrier/ NT-3 overexpressing cells}

The adhesion of NT-3 overexpressing cells on the surface of collagen coated PLGA microspheres was assessed with optical microscopy and fluorescent imaging of DAPI -stained cells. The results showed that cells were attached on approximately $80 \%$ of the collagen coated PLGA microparticles (Figure 6A, B), with 5-10 cells on each microcarrier. Scanning electron microscopy (SEM) images also demonstrated cells with lamellipodia adhered bioadhesive surface of microcarriers (Figure 6C). In contrast, PLGA microparticles without collagen coating exhibit much less tendency for cell adhesion on their surfaces (Figure 6 D-F). As can be seen in Figure 6D cells were made clusters due to the lack of suitable adhesive substrate. Moreover, as there is no sign of nucleus in DAPI staining, it seems that cells were dead after the formation of clusters.

The MTT results show that PLGA microspheres has no cytotoxicity whereas the viability of NT-3 overexpressing cells was significantly increased compared to BMSCs which only received standard culture medium (Figure 7A).

The DA content secreted by cells was assessed to confirm dopaminergic differentiation of NT-3 overexpressing cells. As presented in Figure 7B, DA secreted from NT-3 overexpressing cells was significantly higher than BMSCs as control group after 7 days of culture. It can be also seen that the DA content of NT-3 overexpressing cells' media was increased up to 21 days of culture. 


\section{Discussion}

Parkinson's disease is a progressive debilitating neurodegenerative disorder which is pathologically characterized by relentless degeneration of dopaminergic neurons in the substantia nigra pars compacta [40, 41]. Different methods including drug therapy, cell or gene based therapy have been employed as potential treatments for PD in recent years [18, 42, 43]. Among these therapeutic methods more attention has been paid to the application of gene therapy for PD. Current approaches include the use of various growths and neurotrophic factors encoding genes such as NGF, GDNF, brain derived neurotrophic factors (BDNF), Neurturin (NTN), neurotrophin-3 (NT-3) and neurotrophin-4 (NT-4). Due to the great therapeutic potential of neurotrophic factors (NTFs) many research have been conducted to identify NTFs and their receptors [44, 45]. Neurotrophic factors (NTFs) specifically NT-3 plays an important role during neural system development via regulation of stem cells differentiation to neural lineage and support of their survival after maturation, neurite growth and branching. NT-3 also plays a crucial role in survival of adult nervous system including their effect on normal metabolic activity of neurons, protection from toxins and injury, regulation of neuronal plasticity, and modulation of neurotransmitter synthesis and synaptic activity. Indeed, they regulate neuronal survival and plasticity by activating transmembrane receptor tyrosine kinase (RTK) of Trk family. The potential application of NTFs for treatment of PD specifically by means of transfected MSCs has been previously examined [46]. Neutrotrophin-3 (NT3), one of the neurotrophin members, plays a protective role in injured CNS tissue [47] which makes it a valuable asset for treatment of PD. It has been also shown that the neurotrophin signal transduction through trk receptors could produce positive effects on cell survival, proliferation and axonal myelination of dopaminergic neurons in vivo [12]. However, the application of gene therapy for induction of nerve growth factors expression has been hindered since the transfected cells lack any physical or biological supports $[17,48]$. In addition, numbers of cell based therapies have been employed pluripotent embryonic stem cells which are not reliable cell source as they irritate immunoreaction and increase the risk of tumor formation [11]. Thus, a reliable strategy for PD treatment is still challenging for scientists in different fields [12, 49]. In a multidisciplinary approach, NT-3 overexpressing BMSCs in corporation with PLGA microcarriers optimized and proposed as a potential tool for treatment of Parkinson's disease. BMSCs are excellent candidate as they can differentiate into different lineage including neurons and provide opportunity of autologous cell transplantation which limits the risk of graft rejection 
[2]. The application of cellular scaffold in presence of vital growth factors is essential for efficient long term treatment of neurodegenerative disorders such as Parkinson's disease [10, 12, 27 , 50]. However, the main problem with using growth factor encapsulated PLGA microcarriers is the restricted sources of growth factor which will be depleted even with sustain release over long period of time [17]. Therefore, development of engineered cells that can express and secret signaling molecules in their microenvironment is highly remarkable.

The NT-3 overexpressing BMSCs were prepared via transfecting cells with recombinant PIRES-2-EGFP-NT-3 plasmid DNA using commercially non-viral vector (i.e. Lipofectamine). The results of real-time PCR revealed significant increase in expression of Nurr-1, Wnt-1, Nt-3 and tyrosine hydroxylase. Nurr1 is a nuclear receptor essential for the development of DA neurons. Numerous studies have reported that Nurr1 is vital for both survival and differentiation of the mesencephalic dopaminergic precursor neurons $[45,51,52]$. In addition, it has been reported that Nurr1 can regulate the expression of several genes that are crucial in the synthesis and storage of dopamine [53]. Recently, it has been demonstrated that Nurr1 expression is reduced over the course of normal aging which is one of the main factors in the loss of dopaminergic neuronal phenotype [54]. Pitx3 is a transcription factor that was expressed in both transfected and untransfected BMSCs. Recently; it has been proposed that Nurr1 and Ptx3 synergistically promote terminal maturation to the midbrain neuron phenotype in murine and human embryonic cell cultures [45]. The simultaneous expression of Nurr1 and Ptx3 in BMSCs may be helpful in maturation of these cells to the DA neuron phenotype. Furthermore, Wnt-1 is essential regulator of proliferation and differentiation of ventral midbrain DA precursor neurons [54]. Expression of Wnt1 in BMSCs is another advantage of BMSCs as a candidate for neurological cell therapy.

The successful immunocytochemical staining of transfected BMSCs with anti TH antibodies also approved the enhanced production of tyrosine hydroxylase in transfected cells which is one of the most vital key factors in dopaminergic neuronal development of the cells.

The implementation of tissue engineering in combination with adult stem cells in particular context of brain therapy still remains an emerging field with many limitations. The scaffolds should necessarily be small enough to be able to precisely inject into the skull cavity via stereotactic implantation or under neuronavigation. Furthermore, brain scaffolds must be fully biodegradable and biocompatible for surgical use in order to minimize macrophagic and microglial 
reaction [27]. Thus, the collagen coated PLGA microspheres with the size of $\sim 120 \mu \mathrm{m}$ prepared in this study seems optimal to convey a sufficient amount of cells disturbing the ultrastructure of the tissue after grafting as reported by recent studies [27, 31].

The results of cell culture experiments demonstrated that transfected cells were effectively attached to the bioadhesive surface of microparticles. The HPLC analysis also revealed an elevated secretion of dopamine as an indication of neuronal function of differentiated cells. The increasing rate of dopamin content in cultrure media of microparticle/NT-3 overexpressing cells is implied their successful differentiation to dopaminergic neuronal cell type. Therefore, this system is promissing enough to be implemented as possible interdisiplinary method for treatment of Parkinson's disease. 


\section{Conclusion}

In this study, a combined approach including tissue and genetic engineering that sustained presence of growth factor as a therapeutic method for treatment of PD is proposed. The PLGA microcarriers as a cellular scaffold is designed and optimized in order to support NT-3 overexpressing cells. Indeed, combination of engineered cells with the potential of growth factor production, adhesion molecules and an adapted 3D structure in the same polymeric scaffold suggest an adaptable and very efficient system. This system can possibly deliver stem cells with appropriate cues for enhanced survival, differentiation and integration into the host tissues after implantation.

\section{Acknowledgments}

We gratefully acknowledge the financial support of this work by National Institute of Genetic Engineering and Biotechnology (NIGEB) and Iranian Council of Stem Cell Technology (ICST) (Grant No:920801-III-472) as well as Iran National Science Foundation (INSF- grant No: 91059608). 


\section{References}

1. Delcroix, G.J., et al., Adult cell therapy for brain neuronal damages and the role of tissue engineering. Biomaterials, 2010. 31(8): p. 2105-20.

2. Morizane, A. and J. Takahashi, Cell Therapy for Parkinson's Disease. Neurol Med Chir (Tokyo), 2016. 56(3): p. 102-9.

3. Geffe, S., et al., The single intake of levodopa modulates implicit learning in drug naive, de novo patients with idiopathic Parkinson's disease. J Neural Transm (Vienna), 2016.

4. Wirdefeldt, K., P. Odin, and D. Nyholm, Levodopa-Carbidopa Intestinal Gel in Patients with Parkinson's Disease: A Systematic Review. CNS Drugs, 2016. 30(5): p. 381-404.

5. Higuchi, M.A., et al., Interdisciplinary Parkinson's Disease Deep Brain Stimulation Screening and the Relationship to Unintended Hospitalizations and Quality of Life. PLoS One, 2016. 11(5): p. e0153785.

6. Tronci, E., et al., 5-Hydroxy-tryptophan for the treatment of L-DOPA-induced dyskinesia in the rat Parkinson's disease model. Neurobiol Dis, 2013. 60: p. 108-14.

7. Hindle Fisher, I., et al., Apathy in patients with Parkinson's disease following deep brain stimulation of the subthalamic nucleus. CNS Spectr, 2016: p. 1-7.

8. Hickey, P. and M. Stacy, Deep Brain Stimulation: A Paradigm Shifting Approach to Treat Parkinson's Disease. Front Neurosci, 2016. 10: p. 173.

9. Glavaski-Joksimovic, A. and M.C. Bohn, Mesenchymal stem cells and neuroregeneration in Parkinson's disease. Exp Neurol, 2013. 247: p. 25-38.

10. Lindvall, O. and L.U. Wahlberg, Encapsulated cell biodelivery of GDNF: a novel clinical strategy for neuroprotection and neuroregeneration in Parkinson's disease? Exp Neurol, 2008. 209(1): p. 82-8.

11. Chen, Z., Cell Therapy for Parkinson's Disease: New Hope from Reprogramming Technologies. Aging Dis, 2015. 6(6): p. 499-503.

12. Daviaud, N., et al., Survival, differentiation, and neuroprotective mechanisms of human stem cells complexed with neurotrophin-3-releasing pharmacologically active microcarriers in an ex vivo model of Parkinson's disease. Stem Cells Transl Med, 2015. 4(6): p. 670-84.

13. Ahmed, H.H., et al., Updates in the pathophysiological mechanisms of Parkinson's disease: Emerging role of bone marrow mesenchymal stem cells. World J Stem Cells, 2016. 8(3): p. 106-17.

14. Riecke, J., et al., A Meta-Analysis of Mesenchymal Stem Cells in Animal Models of Parkinson's Disease. Stem Cells Dev, 2015. 24(18): p. 2082-90.

15. Lu, L., et al., Therapeutic benefit of TH-engineered mesenchymal stem cells for Parkinson's disease. Brain Res Brain Res Protoc, 2005. 15(1): p. 46-51.

16. Du, Y., et al., Adeno-associated virus type 2 vector-mediated glial cell line-derived neurotrophic factor gene transfer induces neuroprotection and neuroregeneration in a ubiquitin-proteasome system impairment animal model of Parkinson's disease.

Neurodegener Dis, 2013. 11(3): p. 113-28.

17. Hoban, D.B., L. Howard, and E. Dowd, GDNF-secreting mesenchymal stem cells provide localized neuroprotection in an inflammation-driven rat model of Parkinson's disease. Neuroscience, 2015. 303: p. 402-11.

18. Peaire, A.E., et al., Production of dopaminergic neurons for cell therapy in the treatment of Parkinson's disease. J Neurosci Methods, 2003. 124(1): p. 61-74. 
19. Choi, H.S., et al., Therapeutic potentials of human adipose-derived stem cells on the mouse model of Parkinson's disease. Neurobiol Aging, 2015. 36(10): p. 2885-92.

20. Li, W., S. Chen, and J.Y. Li, Human induced pluripotent stem cells in Parkinson's disease: A novel cell source of cell therapy and disease modeling. Prog Neurobiol, 2015. 134: p. 161-77.

21. Hu, Z., et al., Generation of Naivetropic Induced Pluripotent Stem Cells from Parkinson's Disease Patients for High-Efficiency Genetic Manipulation and Disease Modeling. Stem Cells Dev, 2015. 24(21): p. 2591-604.

22. Berg, J., et al., Human adipose-derived mesenchymal stem cells improve motor functions and are neuroprotective in the 6-hydroxydopamine-rat model for Parkinson's disease when cultured in monolayer cultures but suppress hippocampal neurogenesis and hippocampal memory function when cultured in spheroids. Stem Cell Rev, 2015. 11(1): p. 133-49.

23. Wang, Y., et al., Hypoxia promotes dopaminergic differentiation of mesenchymal stem cells and shows benefits for transplantation in a rat model of Parkinson's disease. PLoS One, 2013. 8(1): p. e54296.

24. Tao, H., R. Rao, and D.D. Ma, Cytokine-induced stable neuronal differentiation of human bone marrow mesenchymal stem cells in a serum/feeder cell-free condition. Dev Growth Differ, 2005. 47(6): p. 423-33.

25. Petschnik, A.E., et al., A novel xenogeneic co-culture system to examine neuronal differentiation capability of various adult human stem cells. PLoS One, 2011. 6(9): p. e24944.

26. Glavaski-Joksimovic, A., et al., Glial cell line-derived neurotrophic factor-secreting genetically modified human bone marrow-derived mesenchymal stem cells promote recovery in a rat model of Parkinson's disease. J Neurosci Res, 2010. 88(12): p. 2669-81.

27. Delcroix, G.J., et al., The therapeutic potential of human multipotent mesenchymal stromal cells combined with pharmacologically active microcarriers transplanted in hemi-parkinsonian rats. Biomaterials, 2011. 32(6): p. 1560-73.

28. Drouin-Ouellet, J., The potential of alternate sources of cells for neural grafting in Parkinson's and Huntington's disease. Neurodegener Dis Manag, 2014. 4(4): p. 297-307.

29. Geldenhuys, W.J., et al., Methyl Yellow: A Potential Drug Scaffold for Parkinson's Disease. Chembiochem, 2014.

30. Daviaud, N., et al., Organotypic cultures as tools for optimizing central nervous system cell therapies. Exp Neurol, 2013. 248: p. 429-40.

31. Tatard, V.M., et al., Pharmacologically active microcarriers releasing glial cell line derived neurotrophic factor: Survival and differentiation of embryonic dopaminergic neurons after grafting in hemiparkinsonian rats. Biomaterials, 2007. 28(11): p. 1978-88.

32. Amensag, S. and P.S. McFetridge, Tuning scaffold mechanics by laminating native extracellular matrix membranes and effects on early cellular remodeling. J Biomed Mater Res A, 2014. 102(5): p. 1325-33.

33. Valmikinathan, C.M., J. Hoffman, and X. Yu, Impact of Scaffold Micro and Macro Architecture on Schwann Cell Proliferation under Dynamic Conditions in a Rotating Wall Vessel Bioreactor. Mater Sci Eng C Mater Biol Appl, 2011. 31(1): p. 22-29.

34. Wei, G.J., et al., Promotion of peripheral nerve regeneration of a peptide compound hydrogel scaffold. Int J Nanomedicine, 2013. 8: p. 3217-25. 
35. Tatard, V.M., et al., In vivo evaluation of pharmacologically active microcarriers releasing nerve growth factor and conveying PC12 cells. Cell Transplant, 2004. 13(5): p. 573-83.

36. Tatard, V.M., et al., Pharmacologically active microcarriers: a tool for cell therapy. Biomaterials, 2005. 26(17): p. 3727-37.

37. Savi, M., et al., Enhanced engraftment and repairing ability of human adipose-derived stem cells, conveyed by pharmacologically active microcarriers continuously releasing HGF and IGF-1, in healing myocardial infarction in rats. J Biomed Mater Res A, 2015. 103(9): p. 3012-25.

38. Terraf, P., H. Babaloo, and S.M. Kouhsari, Directed Differentiation of DopamineSecreting Cells from Nurr1/GPX1 Expressing Murine Embryonic Stem Cells Cultured on Matrigel-Coated PCL Scaffolds. Mol Neurobiol, 2016.

39. Moradian, H., et al., Poly(ethyleneimine) functionalized carbon nanotubes as efficient nano-vector for transfecting mesenchymal stem cells. Colloids Surf B Biointerfaces, 2014. 122: p. 115-25.

40. Arenas, E., Stem cells in the treatment of Parkinson's disease. Brain Res Bull, 2002. 57(6): p. 795-808.

41. Takahashi, J., Stem cell therapy for Parkinson's disease. Expert Rev Neurother, 2007. 7(6): p. 667-75.

42. Armstrong, R.J., et al., Neural stem cell technology as a novel treatment for Parkinson's disease. Methods Mol Med, 2001. 62: p. 289-307.

43. Xu, D.H., et al., Treatment of Parkinson's Disease by Genetically Modified Immortalized Fibroblasts. Sheng Wu Hua Xue Yu Sheng Wu Wu Li Xue Bao (Shanghai), 2001. 33(1): p. 117-122.

44. Ye, M., et al., Transplantation of bone marrow stromal cells containing the neurturin gene in rat model of Parkinson's disease. Brain Res, 2007. 1142: p. 206-16.

45. Lei, Z., et al., Signaling of glial cell line-derived neurotrophic factor and its receptor GFRalphal induce Nurrl and Pitx3 to promote survival of grafted midbrain-derived neural stem cells in a rat model of Parkinson disease. J Neuropathol Exp Neurol, 2011. 70(9): p. 736-47.

46. Bibel, M. and Y.A. Barde, Neurotrophins: key regulators of cell fate and cell shape in the vertebrate nervous system. Genes Dev, 2000. 14(23): p. 2919-37.

47. Kusano, K., et al., Transplanted neural progenitor cells expressing mutant NT3 promote myelination and partial hindlimb recovery in the chronic phase after spinal cord injury. Biochemical and Biophysical Research Communications, 2010. 393(4): p. 812-817.

48. Han, F., et al., Development of stem cell-based therapy for Parkinson's disease. Transl Neurodegener, 2015. 4: p. 16.

49. Huot, P., S.H. Fox, and J.M. Brotchie, Dopamine Reuptake Inhibitors in Parkinson's Disease: A Review of Nonhuman Primate Studies and Clinical Trials. J Pharmacol Exp Ther, 2016. 357(3): p. 562-9.

50. Scholten, M., et al., Cortical correlates of susceptibility to upper limb freezing in Parkinson's disease. Clin Neurophysiol, 2016. 127(6): p. 2386-93.

51. Jiang, C., et al., Dopaminergic properties and experimental anti-parkinsonian effects of IPX750 in rodent models of Parkinson disease. Clin Neuropharmacol, 2004. 27(2): p. 6373. 
52. Hering, R., et al., Extended mutation analysis and association studies of Nurr1 (NR4A2) in Parkinson disease. Neurology, 2004. 62(7): p. 1231-2.

53. Zheng, K., B. Heydari, and D.K. Simon, A common NURR1 polymorphism associated with Parkinson disease and diffuse Lewy body disease. Arch Neurol, 2003. 60(5): p. 7225.

54. Blaudin de The, F.X., et al., Neuroprotective Transcription Factors in Animal Models of Parkinson Disease. Neural Plast, 2016. 2016: p. 6097107. 
Table 1. The sequence of primers used for real-time PCR.

\begin{tabular}{lll}
\hline Gene & Forward primer (50-30) & Reverse primer (50-30) \\
\hline GAPDH & GCACCGTCAAGGCTGAGAAC & ATGGTGGTGAAGACGCCAGT \\
\hline En1 & CTGGGTGTACTGCACACGTTAT & TACTCGCTCTCGTCTTTGTCCT \\
\hline Pitx3 & CCTACGAGGAGGTGTACCCC & AGGCGAATGGAAAGGTCTTGG \\
\hline Pax2 & TGTCAGCAAAATCCTGGGCAG & GTCGGGTTCTGTCGTTTGTATT \\
\hline Nurr1 & GCACTTCGGCAGAGTTGAATGA & GGTGGCTGTGTTGCTGGTAGTT \\
\hline Wnt1 & CGGCGTTTATCTTCGCTATCA & GCAGGATTCGATGGAACCTTCT \\
\hline Nt-3 & TCAAAACGGGCAACTCTCCT & CTCGACAAGGCACACACACA \\
\hline Th & GTCCCCTGGTTCCCAAGAAAAGT & TCCAGCTGGGGGATATTGTCTTC \\
\hline
\end{tabular}


Table 2. The main parameters in PLGA microcarrier synthesis along with their mean diameter and polydispersity index.

\begin{tabular}{ccccc}
\hline No. & Organic solvent & $\begin{array}{c}\text { Speed of } \\
\text { mechanical stirring }\end{array}$ & $\begin{array}{c}\text { Mean diameter } \\
(\boldsymbol{\mu m})\end{array}$ & PDI \\
\hline 1 & Ac:DiCh (40:60) & $200 \mathrm{rpm}$ & 180.27 & 1.021 \\
\hline 2 & Ac:DiCh (30:70) & $200 \mathrm{rpm}$ & 168.28 & 1.05 \\
\hline 3 & Ac:DiCh (20:80) & $200 \mathrm{rpm}$ & 156.27 & 1.59 \\
\hline 4 & Eth:DiCh (40:60) & $200 \mathrm{rpm}$ & 205.90 & 0.85 \\
\hline 5 & Eth:DiCh (30:70) & $200 \mathrm{rpm}$ & 179.42 & 0.75 \\
\hline 7 & Eth:DiCh (30:70) & $300 \mathrm{rpm}$ & 123.23 & 1.22 \\
\hline 8 & Eth:DiCh (20:80) & $200 \mathrm{rpm}$ & 130.39 & 0.96 \\
\hline 10 & DiCh (100) & $200 \mathrm{rpm}$ & 135.25 & 0.84 \\
\hline
\end{tabular}

Ac: Acetone, DiCh: Dichloromethane, Eth: Ethyl acetate 


\section{Figure Captions}

Table 1. The sequence of primers used for real-time PCR.

Table 2. The main parameters in PLGA microcarrier synthesis along with their mean diameter and polydispersity index.

Figure. 1 Schematic procedure of recombinant pDNA preparation (A). The sequence analysis of NT-3 protein that shows the presence of signal peptide (B). The agarose gel electrophoresis of plasmid DNA (pIRES-2EGFP) before (lane 1,2) and after recombination (i.e. pIRES-2-EGFPNT-3) ( lane 3,4), recombinant pDNA digested with one (lane 5) or two (lane 6) restriction enzyme.

Figure. 2 The optical (A) and florescent (B) image of one transfected cell that successfully expressed enhanced green florescent protein (EGFP).

Figure. 3 The real-time PCR analysis of neuronal differentiation genes (A). There is significant differences $(p<0.05)$ between expression of nurr-1, wnt-1, nt-3 and th mRNAs in BMSCs and neuro-differentiated cells. Optical (B), fluorescent image of cells stained with anti- TH antibodies (C), dapi-neuclo stained cells (D) and merged image (E) of differentiated cells.

Figure. 4 The particle size analysis (A), optical image of optimum PLGA microcarriers (B). SDS-PAGE result (C) of collagen (1), PLGA functionalized with collagen (2) and protein marker (M). Two bonds in dissolved functionalized microcarriers verified the successful attachment of collagen to PLGA surface.

Figure. 5 Scanning electron microscopy (SEM) images of PLGA microspheres before (A, B) and after (C,D) coating their surface with collagen. The stability (gradual degradation) of PLGA microcarriers are also presented after one week $(\mathrm{E}, \mathrm{F})$ and one month $(\mathrm{G}, \mathrm{H})$.

Figure. 6 Evaluation of collagen coated PLGA microparticles with optical microscopy analysis (A) fluorescent image of DAPI stained cells (B), and SEM (C). Microparticles without collagen coating are also presented in (D-F). SEM images confirmed successful adhesion of cells on the surface of collagen coated microcarriers (C), in contrast there is almost no cell adhesion on microparticles without collagen coating $(\mathrm{F})$.

Figure. 7 The cell viability was evaluated via MTT test at 1, 2, and 7 days (A). The DA content measured by HPLC showing significant difference at day $7\left(*^{*}<0.05\right)(\mathrm{B})$. 


\section{Graphical Abstract}

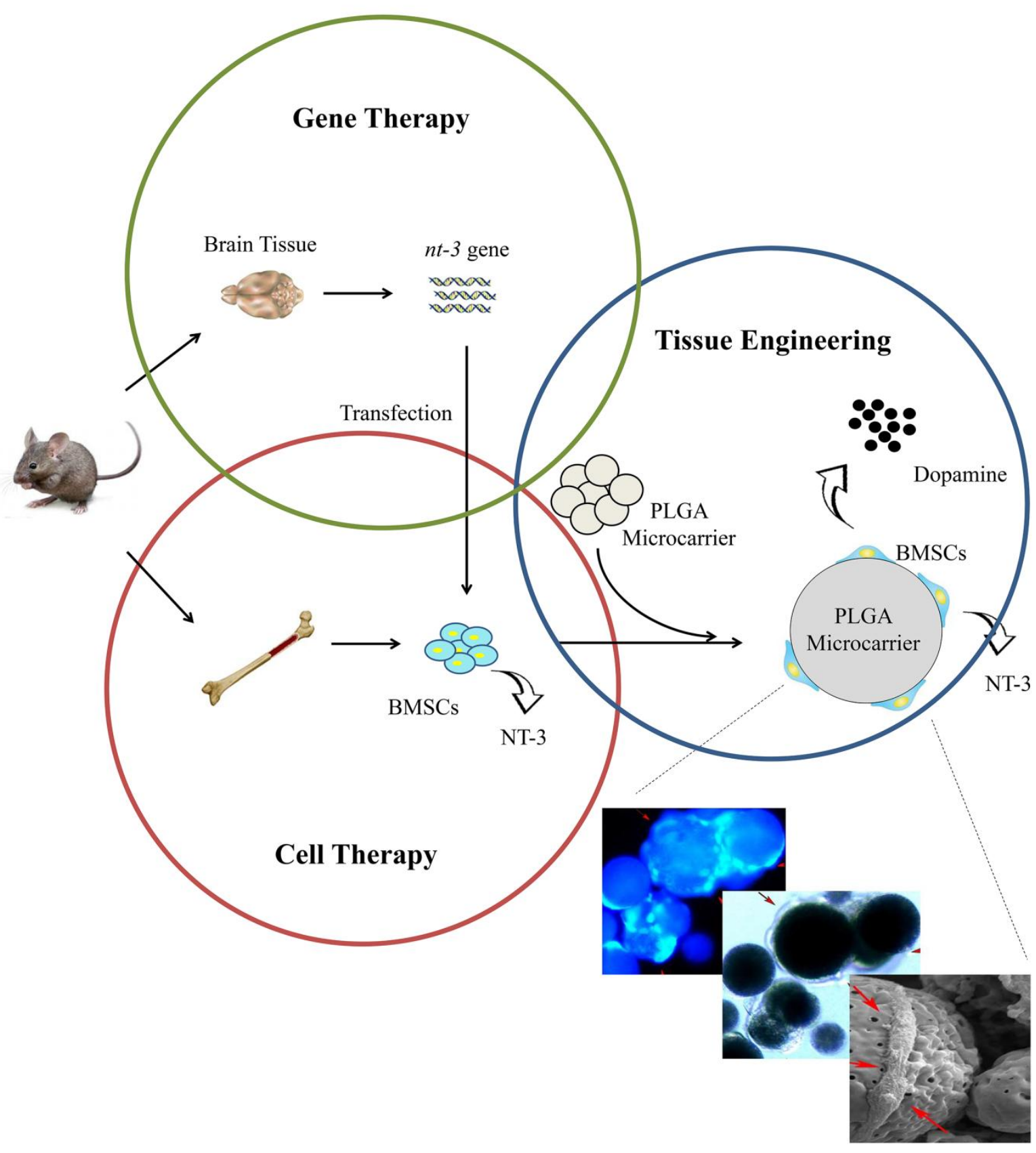




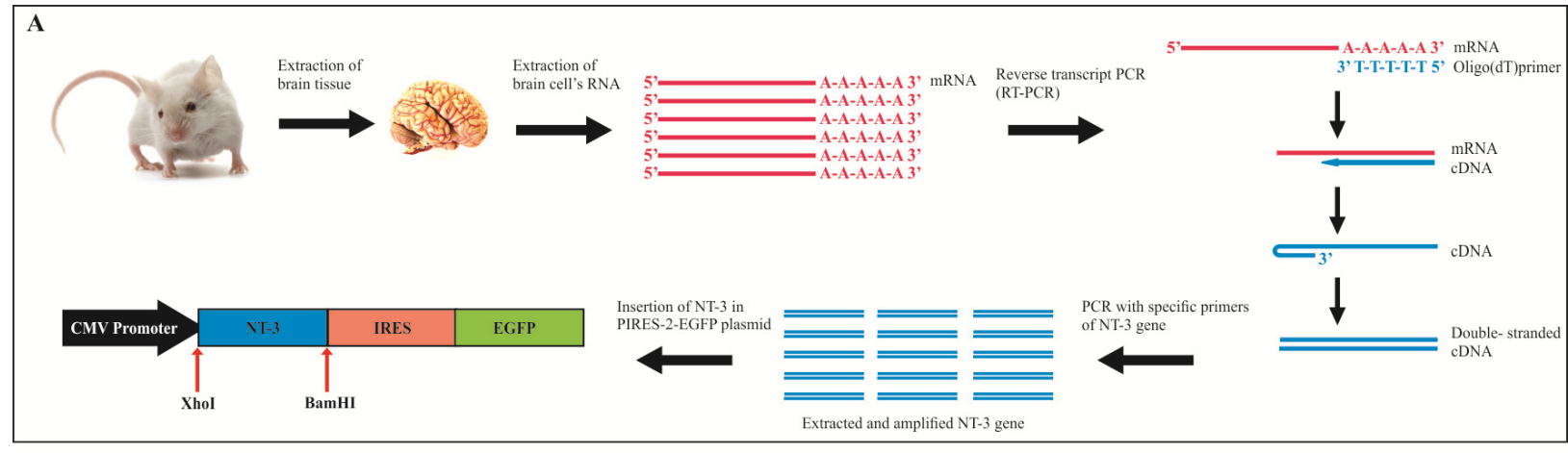

B

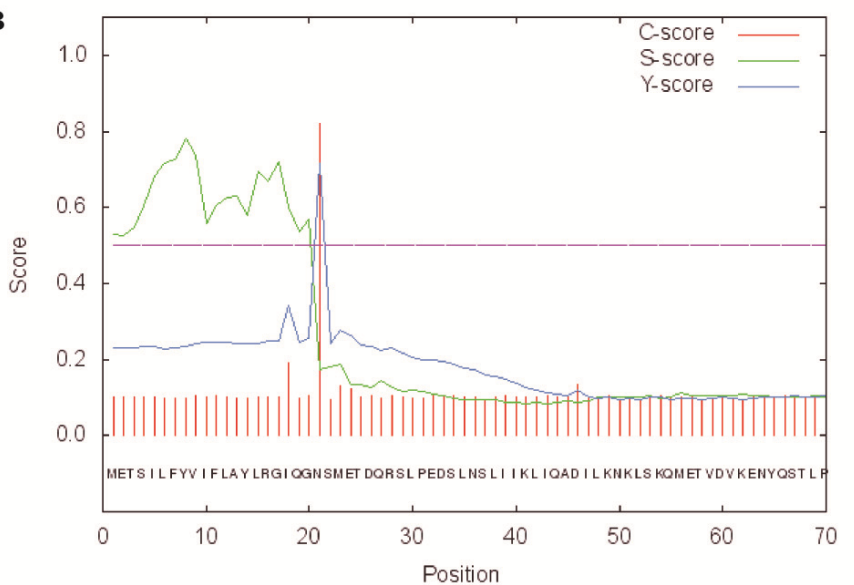

C

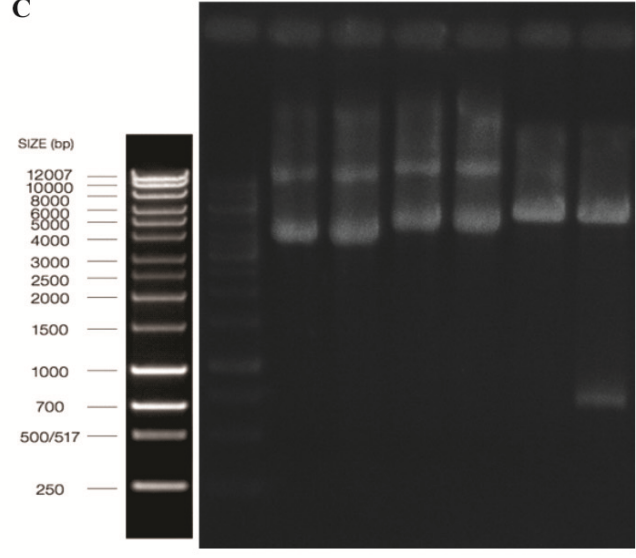

Figure 1. 


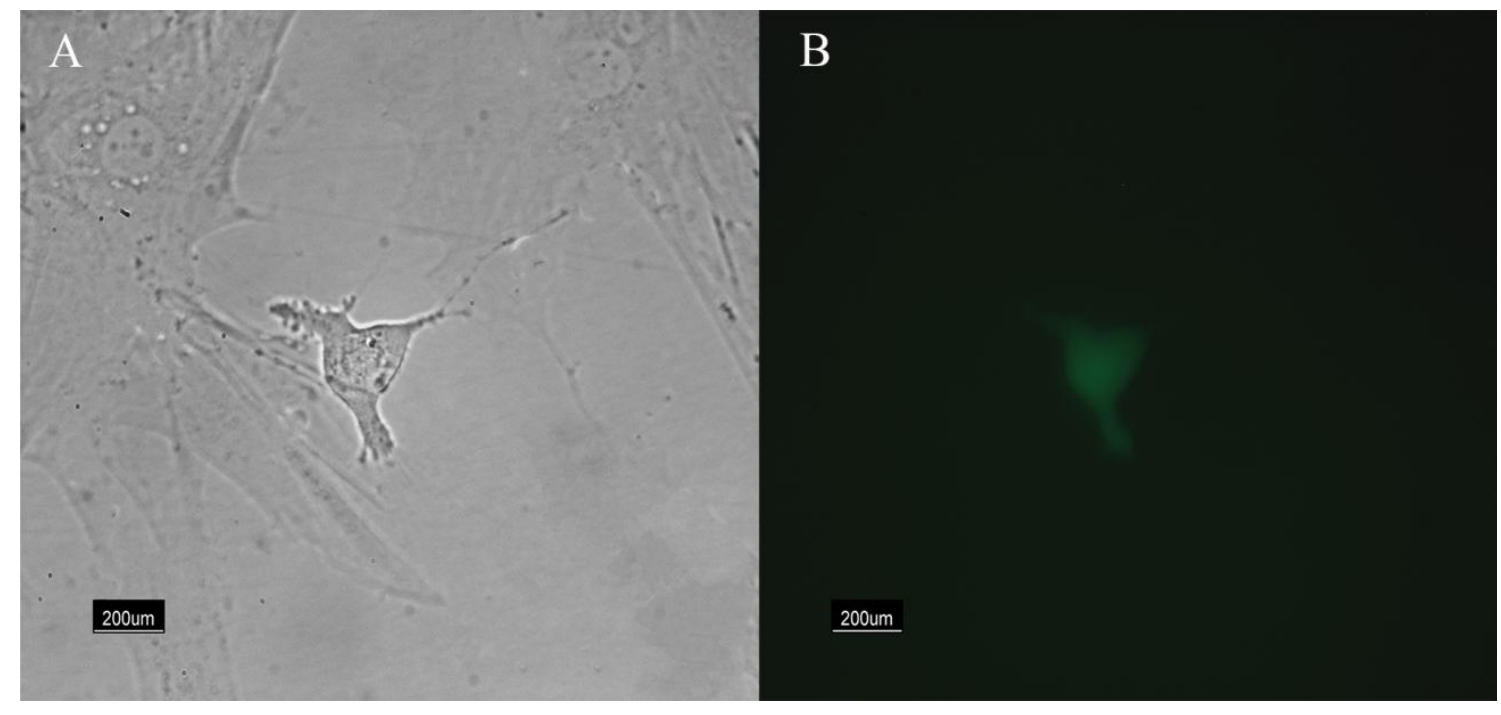

Figure 2. 


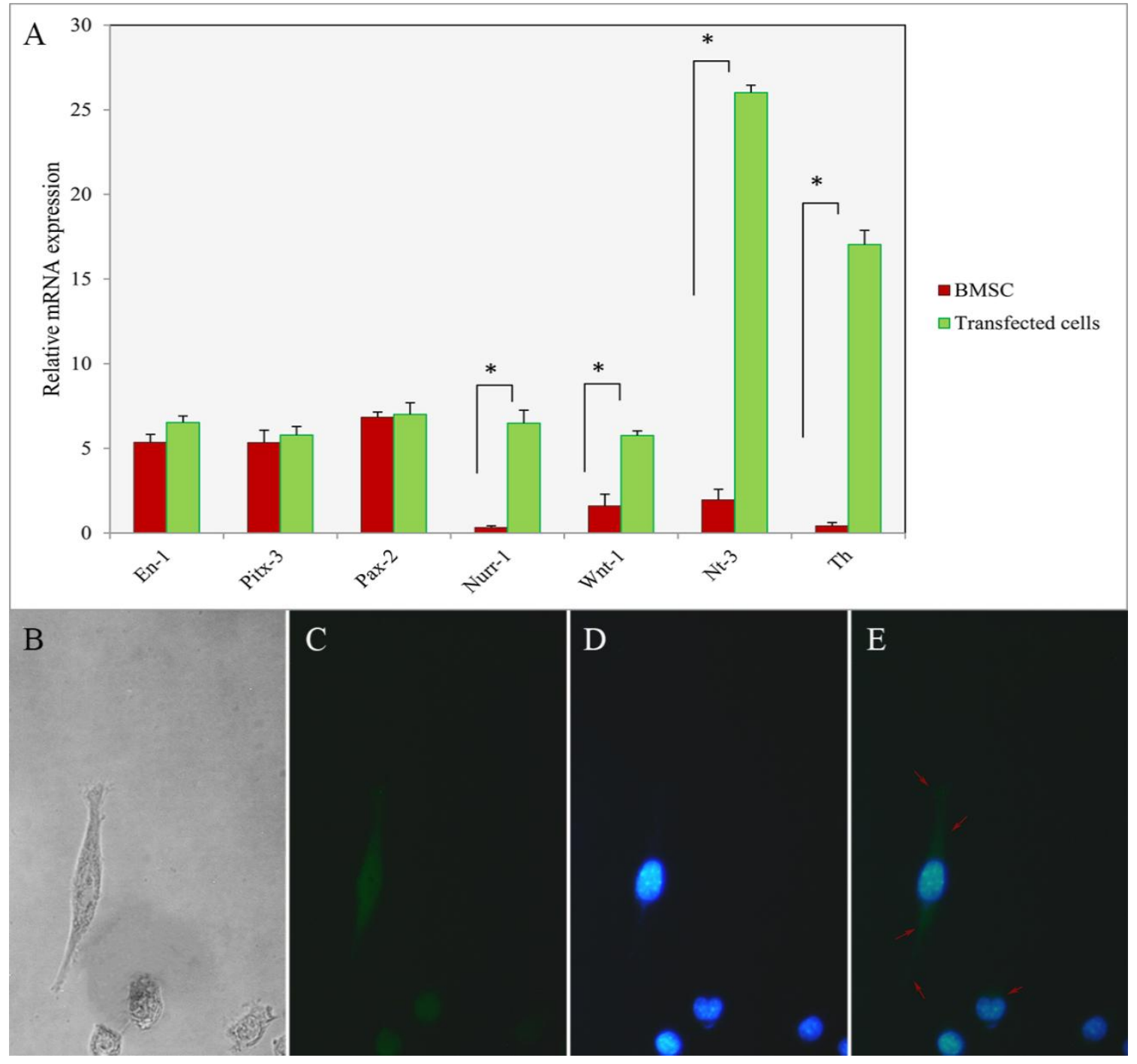

Figure 3. 

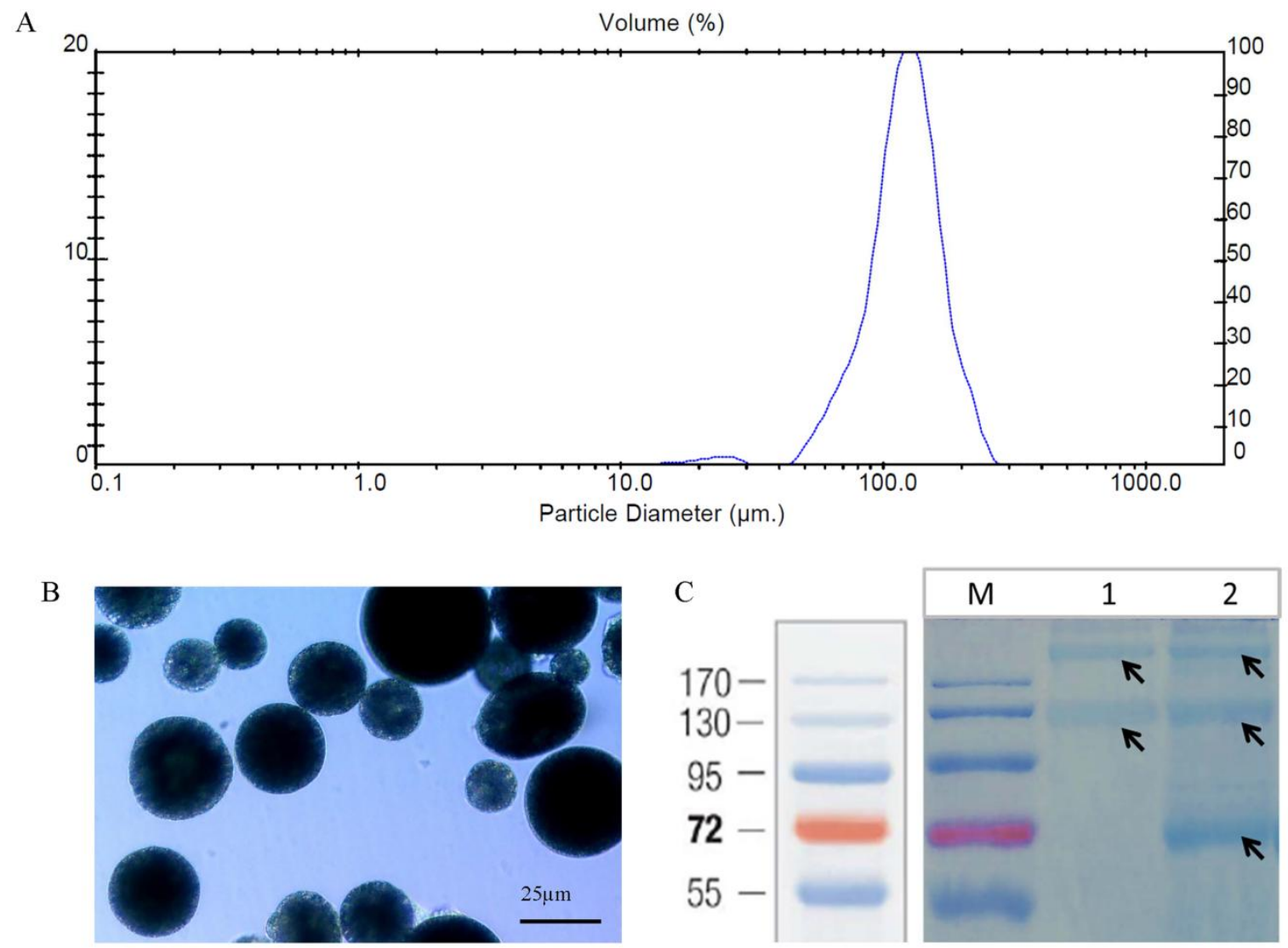

Figure 4. 

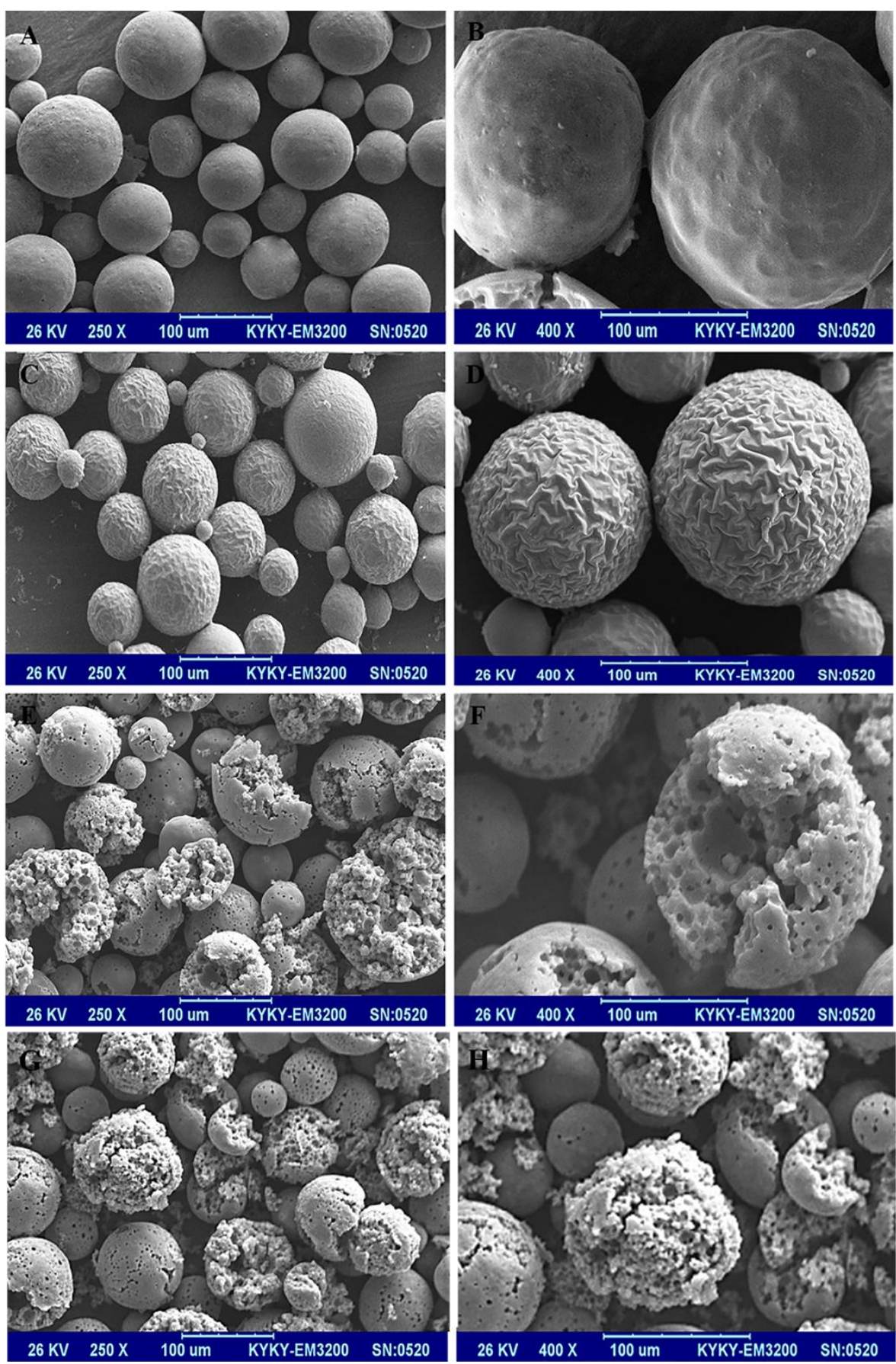

Figure 5. 

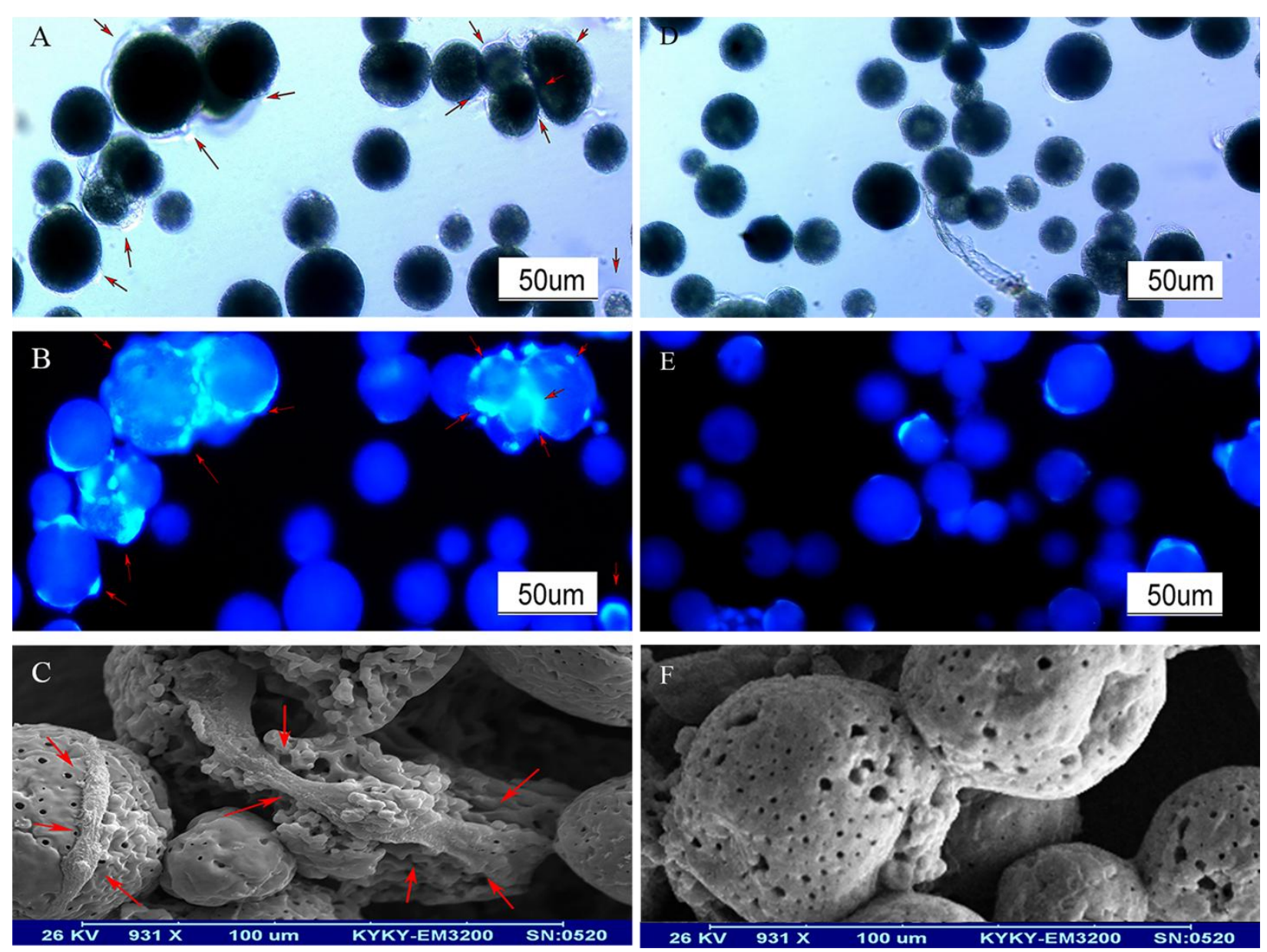

Figure 6. 


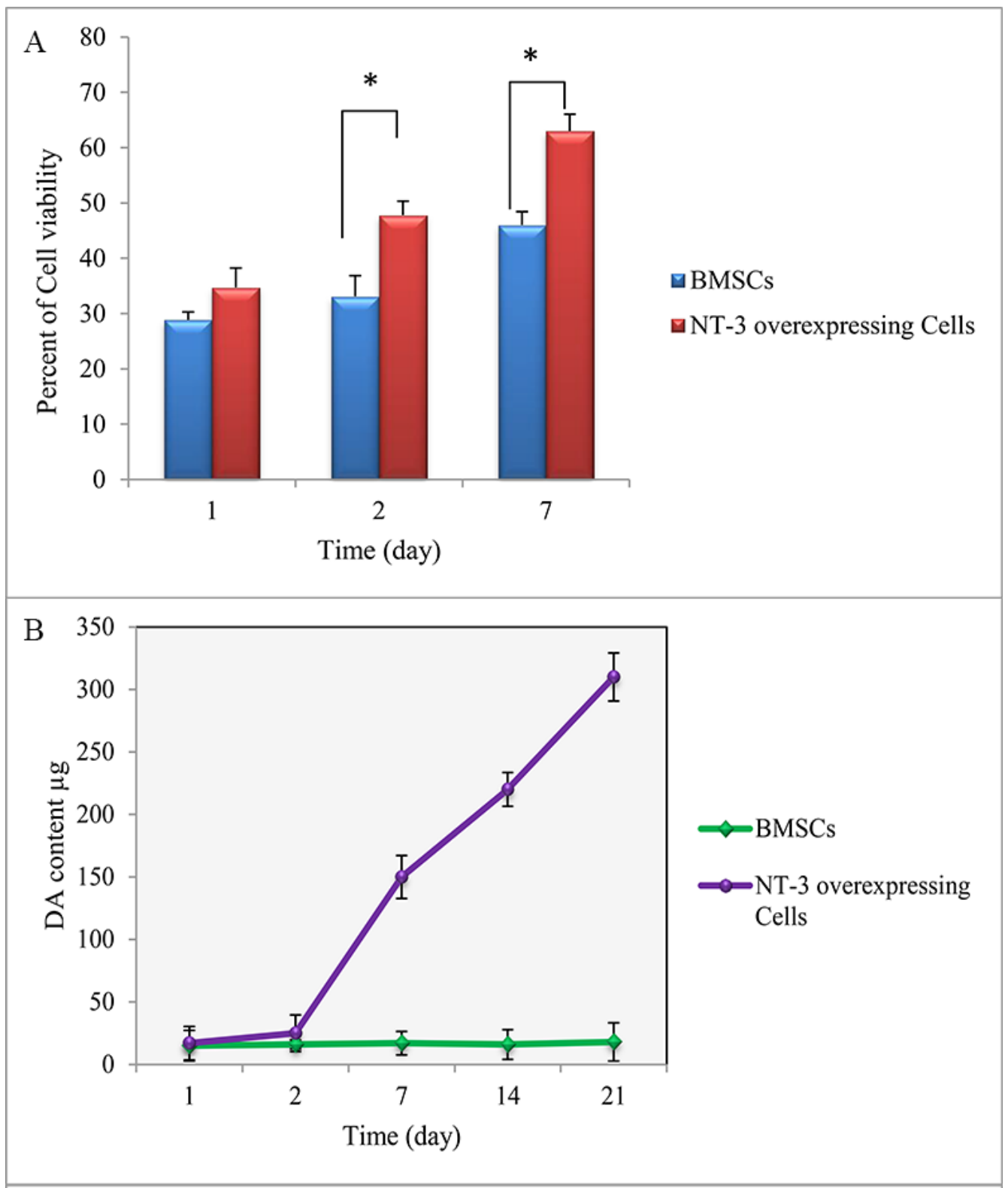

Figure 7. 